\title{
Mortality, hospital days and treatment costs of current and reduced sugar consumption in Israel
}

\author{
Gary M. Ginsberg
}

\begin{abstract}
Background: Consumption of sugar causes tooth decay, overweight and obesity related morbidities. This paper in response to the Minister of Health's request, provides estimates of the mortality, morbidity and health care costs attributable to sugar consumption in Israel along with the effects of reducing sugar consumption.

Methods: Gender specific relative risks of many diseases from overweight $(25<=\mathrm{BMl}<30)$ and obesity $(\mathrm{BMI}>=30)$ were applied to the national gender specific prevalence rates of overweight and obesity in order to calculate the population attributable fraction (PAF) from overweight and obesity. National expenditure on these related diseases was calculated by applying disease-specific data from a recent Canadian study to estimates of disease specific general hospital expenditures in Israel. Disease specific costs attributable to overweight and obesity were estimated from the product of these expenditures and PAF. In addition national costs of treating caries in persons under 18 years of age from sugar were calculated. Similar calculations were made to estimate the burden from sugar in terms of mortality and hospital utilisation. A recent UK modelling study was used to estimate the effect of a national program to reduce calorific consumption of sugar from 12.45 to $10 \%$ in 5 years.
\end{abstract}

Results: Conditions associated with overweight or obesity accounted annually for 6402 deaths (95\% Cl 3296-8760) and 268,009 hospital days. Dental costs attributable to sugar consumption were 264 million NIS. In total, obesity, overweight and sugar consumption accounted for 2449 million in direct treatment costs ( $0.21 \%$ of GDP), rising to 4027 million ( $0.35 \%$ of GDP) when indirect costs were included. A national program of reducing energy from sugar consumption from 12.45 to $10 \%$ over 5 years is considered have a very feasible short-term goal. Even if the program does not impose taxes on sugar consumption, this would save 778 million NIS as well as 1184 lives.

Conclusion: Sugar consumption causes a huge monetary and mortality burden. Estimates of potential decreases in this burden justify the current prioritisation given by the health minister of creating and implementing a national program to reduce sugar consumption, which is likely to be cost-saving (ie: averted treatment costs will exceed intervention costs).

Keywords: Attributable mortality, Hospitalisations, Sugar, Obesity, Overweight

Correspondence: gary.ginsberg@moh.health.gov.il

Israel Ministry of Health, Public Health Services, Yirmiahu Street 39, Jerusalem 9446724, Israel 


\section{Background}

The increasing prevalence of obesity, which has more than doubled since 1980 [1] is an important public health problem that contributes to excess morbidity and, to a lesser degree, increased mortality [2]. In 2000, the World Health Organization (WHO) attributed $7-25 \%$ of total health care costs worldwide [2] to obesity. In 2014, worldwide, there were over 1.9 billion overweight $(25=<$ Body Mass Index $[\mathrm{BMI}]<30)$ in addition to more than 600 million obese adults $(\mathrm{BMI} \geq 30)$. Elevated BMI is associated with a higher risk of many non-communicable diseases [1].

Overweight and obesity, as well as their related noncommunicable diseases, are largely preventable. It is acknowledged that there exists a multiplicity of measures to prevent overweight or obesity such as encouraging physical activity [3], reducing alcohol intake [4] and reducing daytime napping [5]. However, the fundamental cause of overweight and obesity is an energy imbalance between calories consumed and calories expended.

At the individual level, people can

a) Limit their energy intake from total fats and sugars [1];

b) Increase their consumption of fruit, vegetables, legumes, whole grains and nuts [1]

c) Engage in regular physical activity [1, 3].

Individual responsibility can only have its full effect where people have access to a healthy lifestyle. Therefore, at the societal level it is important to undertake policies that support individuals to engage in regular physical activity and make healthier dietary choices [1].

Consuming too much sugar and too many foods and drinks high in sugar content, causes not only tooth decay [6] but also weight gain [7] leading to subsequent overweight and obesity related morbidities. A recent report from the United Kingdom (UK) [8] proposed the following multifaceted approach in order to decrease calorific consumption from sugars.

a) A gradual reduction of sugar content in everyday food and drink products, combined with reductions in portion size.

b) Price increases of a minimum of $10-20 \%$ on high sugar products through the use of a tax or levy such as on full sugar soft drinks [9].

c) Reduction in price promotions in all retail outlets including supermarkets, stores, restaurants and takeaways.

d) Reduction in advertisements for high sugar food and drink products to children and adults.

e) Implementation of public sector catering standards to ensure provision and sale of healthier food and drinks in hospitals, leisure centers etc. f) Encourage health promotion by providing practical steps to help individuals lower their own and their families' sugar intake.

Just as in other developed and developing countries, Israelis are not immune from being overweight or obese and their related morbidities [10].

This paper is a response to the request of the Minister of Health, to provide an estimate as to the potential reduction in mortality, morbidity and health care costs if a national program (containing many elements similar to that proposed in the UK [8]), but with the addition of labelling of products with high sugar content [11], to reduce calorific intake from sugar consumption is adopted and implemented in Israel.

\section{Methods}

Prevalence

Estimates of the gender, religion (Jews and non-Jews) and age-specific $(20-64,65+)$ measured prevalence rates of overweight and obesity in Israel in 2016, were based on extrapolations and interpolations of data from a number of national surveys on self-reported [12-14] and measured $[15,16]$ rates of overweight and obesity.

\section{Relative risks}

Cause and gender-specific data on relative risks (along with 95\% Confidence Intervals) for 16 diagnoses were obtained from a Canadian cost of illness study based on meta-analyses [17] and from a more recent metaanalyses for type II diabetes [18], non-alcoholic fatty liver disease [19] and gout [20], the latter two diagnosis specific risks being based on average BMI levels of 27.3 and 33.6 in Israeli overweight and obese persons respectively [21].

\section{Population attributable fraction (PAF)}

The gender and diagnosis specific PAF, were calculated, for both the prevalence of overweight and obesity in turn using the following standard formula:-

$$
\mathrm{PAF}=\frac{\text { prevalence } \times(\mathrm{RR}-1)}{[\text { prevalence } \times(\mathrm{RR}-1)+1]}
$$

The resultant PAF were then aggregated across genders and combined for overweight and obesity in order to arrive at a composite diagnosis specific PAF.

\section{Hospital expenditures}

Age, gender and cause specific data on days hospitalization in general hospitals for persons over 20 in 2016 were estimated by applying the average age, gender and cause specific hospitalization rates in persons aged 20+ from 2010 to 2013 (Personal communication, Tziona Haklaii and 
Nehama Goldberger of the Health Ministry's Information Division) to the age and gender specific population data for 2016, which in turn was based on extrapolations of data from 2013 to 2015 [22-24]. Total general hospital costs for diseases associated with overweight and obesity were calculated by multiplying the disease specific utilisation data by the per day costs (2127-2613 NIS) associated with their respective departments [25] and the disease specific utilization of intensive care units costing around 5852 NIS per day [26]. The resultant figure was then multiplied by a factor of 1.33 [23] to take into account utilisation of geriatric hospitals, rehabilitation and convalescent facilities as well as associated research costs (which are an integral part of providing quality medical care in hospitals).

\section{Direct health expenditures}

Cause specific costs of out of hospital pharmaceutical use and other services (eg; ambulatory, emergency room, out- patient visits etc.) were estimated by applying cost ratios from a Canadian study [17] to the Israeli based hospital expenditures

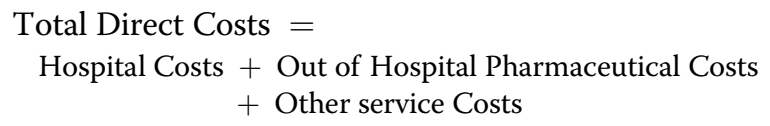

\section{Productivity losses and other indirect costs}

Estimates of indirect costs included mainly productivity losses, due to increased absenteeism and presenteeism (i.e. workers coming in to work, but with impaired productivity due to their health condition), in addition to informal carers costs and transport costs. Imputed human capital costs from premature mortality were excluded as these are in effect "virtual" costs, but frictional employment costs (i.e.; retraining substitute workers to replace the deceased worker) were included. Estimates of the ratio of indirect costs relative to health service costs were based on international published literature [17, 27-41], where information was available that enabled distinction between human capital valuations of mortality and other indirect costs. This ratio was then multiplied by the calculated direct health services costs in order to provide cause specific estimates for indirect costs resulting from overweight and obesity. Since categorizations of indirect costs are not always homogeneous, we used a sensitivity analysis based on the semi-interquartile range for confidence limits around our median estimate.

$$
\begin{aligned}
\text { Total Societal Costs }= & \text { Direct Health Expenditures } \\
& + \text { Productivity Losses } \\
& + \text { Care Costs } \\
& + \text { Transport Costs. }
\end{aligned}
$$

The disease-specific product of these expenditures and PAF estimated the various cost of these diseases.

\section{Dental fillings}

Israelis consume on average $22.9 \mathrm{~kg}$ per capita $(62.7 \mathrm{~g}$. per day) of sugar annually [23], this provides $12.45 \%$ of all calorific intake in Israel [23] similar to the figure of $12.06 \%$ in the UK [7]. A cross-section of international data [42], enabled the calculation of the prevalence of caries attributable to sugar, based on regression coefficient slopes of 0.02 (intercept of no sugar consumption estimates 2.13 caries) in milk teeth (in persons aged 6.5 years old) and 0.04 (intercept of 0.06 ) caries per gm. per person per day in adult teeth (in persons aged 12.5 years old), This figure was then divided by the amount of sugar consumed by the two groups in order to estimate the annual caries incidence per exposed tooth year attributable to sugar consumption and other causes in Israel. In keeping with guidelines from the UK, we only included the impact of sugar consumption and changes in the incidence of dental caries in children and young adults (under 18 years of age), because the development of dental caries depends on life-long exposure to risk factors [43].

The following formula was used for milk and adult teeth in turn, aggregated up to 18 years old:-

$$
\begin{aligned}
& \text { Incidence of caries }=\text { Incidence per tooth year } \\
& \times \text { number of tooth years in population } \\
& \times(100 \%-\% \text { decrease due to fluoridation })
\end{aligned}
$$

Assuming fluoride in the water supply reduces caries by $35.5 \%$ (95\% CI $25.7-45.3 \%)$ in milk teeth and $26.4 \%$ (95\% CI 16.4-36.6\%) in adult teeth [44].

\section{Cost of fillings}

Cost of fillings were based on sick fund specific costs (ranging from 162 to 193 NIS for a single surface and 253-596 NIS for multiple surfaces) in proportion to their membership [45] and private dental costs (150-600 NIS), assuming $40 \%$ were carried out by independent private dentists.

\section{Mortality}

Gender and cause specific data on mortality for persons over twenty years old in 2016 were estimated by applying the average age, gender and cause specific mortality rates in persons aged 20+ from 2009 to 2013 (Personal communication, Tziona Haklaii and Nehama Goldberger of the Health Ministry's Information Division) to the aforementioned age and gender specific population data for 2016 [22-24].

These cause and gender specific deaths were then multiplied by the cause and gender specific PAFs in order to estimate the number of deaths attributable to overweight and obesity in 2016.

\section{Potential Years of Life Lost (PYLL)}

Extrapolations of age and gender specific life expectancies to 2016 [22, 23] were multiplied by age-gender and cause 
specific mortality data in order to calculate the cause specific PYLL attributable to overweight and obesity.

\section{Disability Adjusted Life Years (DALY)}

Age- and gender-specific disability weights, used by the Ministry of Health, were applied to the life expectancies in $2016[22,23]$ in order to calculate the age and gender specific Healthy Adjusted Life Expectancy (HALE), subject to a 3\% per annum discount rate. These HALEs were subsequently multiplied by the age-gender and cause specific mortality data from 2010 to 2013 (Personal communication, Tziona Haklaii and Nehama Goldberger of the Health Ministry's Information Division) in order to calculate the cause specific DALY loss due to mortality.

\section{DALY loss due to morbidity}

Due to lack of cause specific disability weights, we assumed that each days hospitalization resulted in a disability weight of 0.3 (varied using a sensitivity analysis between 0.2 and 0.4 ), which was then multiplied by the age-and gender specific hospitalization rates adjusted by the Ministry of Health's age- and gender-specific disability weights of health people in order to estimate the DALY losses due to morbidity.

\section{Sugar reduction}

Data from a recent UK modelling study [8] was used to estimate the effect on mortality, morbidity and costs of reducing calorific consumption of sugar from 12.45 to $10 \%$ in 5 years (a feasible short-term goal) or to $5 \%$ in fifteen years (a harder to attain long-term goal) by means of a multi-faceted National program.

\section{Cost utility analysis}

The basic formulae used for calculating the cost per averted DALY loss is:-

$$
\text { Cost per averted DALY loss }
$$

$$
=\frac{\text { Cost of intervention }- \text { Tax revenues }- \text { Savings in costs }}{\text { Averted DALY losses }}
$$

where:-

From the health services perspective:

Savings in costs $=$ Reduction in direct treatment costs

From the Societal perspective:

Savings in costs $=$ Reduction in (direct treatment + productivity losses + other indirect costs).

Averted DALY losses $=$ Averted DALY losses due to morbidity and mortality decreases.

All costs are presented in new Israeli shekels (NIS) at 2016 price levels. (at an exchange rate of 3.86 NIS to
US dollar). Israel has no official policy guidelines for defining whether or not a health intervention is costeffective. Affordability of interventions is a function of the amount of resources available in a country as proxied by its Gross Domestic Product (GDP) per capita. Therefore, WHO guidelines were used, which define an intervention as being very cost-effective [46] if the cost per DALY averted is less than the GDP per capita of 136,907 NIS $(\$ 35,427)$ in Israel $[22-24,47]$.

Estimated sugar tax revenues were based on recent UK estimates of 520,000,000 lb sterling per annum from just taxing soft drinks [48] adjusted for differences in population size and GNP per capita.

\section{Results}

Table 1 shows the high estimated prevalence of overweight and obesity in 2016 for both genders aged 20-64 and the even higher prevalence in the over $65 \mathrm{~s}$, especially amongst non-Jewish females. There are around 2,056,000 overweight and 1,719,000 obese adults in Israel.

Disease specific relative risks for overweight and obesity are especially elevated for type II diabetes (both genders), pulmonary embolisms (both genders), osteoarthritis (males) and coronary arterial disease (females) (Table 2).

Estimated direct costs of comorbidities related to overweight and obesity in Israelis aged over 20 years old were around 4763 million NIS of which hospital care accounted for $44.8 \%$ and pharmaceutical consumption outside of hospitalization 24.2\% (Appendix 1).

Since the PAF for Type II Diabetes exceeded 100\%, we constrained its PAF to be an arbitrary $90 \%$. Around 6402 people (95\% CI 3296-8760) died in 2016 (Table 3) as a result of conditions associated with them being overweight (2315 deaths: 95\% CI 695-3535) or obese (4086 deaths: 95\% CI: 26005225). The leading causes of death were Coronary Artery Disease which accounted for 2207 (95\% CI: 1763-2649) fatalities (34.5\% of all attributable deaths),

Table 1 Overweight and obesity prevalence by gender, religion and age (2016)

\begin{tabular}{lll}
\hline & Overweight & Obese \\
\hline $20-64$ & & \\
Jewish males & $32.7 \%$ & $21.9 \%$ \\
Jewish females & $23.2 \%$ & $19.5 \%$ \\
Non-Jewish males & $32.5 \%$ & $24.1 \%$ \\
Non-Jewish females & $27.3 \%$ & $29.6 \%$ \\
$65+$ & & \\
Jewish males & $43.5 \%$ & $31.2 \%$ \\
Jewish females & $30.8 \%$ & $27.8 \%$ \\
Non-Jewish males & $43.2 \%$ & $34.3 \%$ \\
Non-Jewish females & $36.2 \%$ & $42.2 \%$ \\
\hline
\end{tabular}


Table 2 Disease-specific relative risks for overweight and obese persons by gender

\begin{tabular}{|c|c|c|c|c|c|}
\hline & \multicolumn{2}{|c|}{ Overweight } & \multicolumn{2}{|c|}{ Obese } & \multirow[t]{2}{*}{ Ref. } \\
\hline & Male & Female & Male & Female & \\
\hline Asthma & 1.20 & 1.25 & 1.43 & 1.78 & [14] \\
\hline Breast cancer & 1.00 & 1.08 & 1.00 & 1.13 & [14] \\
\hline Congestive heart failure & 1.31 & 1.27 & 1.79 & 1.78 & [14] \\
\hline Colorectal cancer & 1.51 & 1.45 & 1.95 & 1.66 & [14] \\
\hline Coronary artery disease & 1.29 & 1.80 & 1.72 & 3.10 & [14] \\
\hline Diabetes type II & 2.20 & 3.60 & 6.05 & 11.15 & {$[14,15]$} \\
\hline Endometrial cancer & na & 1.53 & na & 3.22 & [14] \\
\hline Gallbladder disease & 1.09 & 1.44 & 1.43 & 2.32 & [14] \\
\hline Gout & 2.02 & 1.79 & 3.70 & 2.95 & [20] \\
\hline Hypertension & 1.28 & 1.65 & 1.84 & 2.42 & [14] \\
\hline Kidney cancer & 1.40 & 1.82 & 1.82 & 2.64 & [14] \\
\hline Non-alcoholic fatty liver & 1.30 & 1.52 & 4.09 & 4.78 & [19] \\
\hline Esophageal cancer & 1.13 & 1.15 & 1.21 & 1.20 & [14] \\
\hline Osteoarthritis & 2.76 & 1.80 & 4.20 & 1.96 & [14] \\
\hline Ovarian cancer & na & 1.18 & na & 1.28 & [14] \\
\hline Pancreatic cancer & 1.28 & 1.24 & 2.29 & 1.60 & [14] \\
\hline Prostate cancer & 1.14 & 1.00 & 1.05 & 1.00 & [14] \\
\hline Pulmonary embolism & 1.91 & 1.91 & 3.51 & 3.51 & [14] \\
\hline Stroke & 1.23 & 1.15 & 1.51 & 1.49 & [14] \\
\hline
\end{tabular}

Type II Diabetes (13.2\%), Congestive Heart Failure (12.8\%), Stroke (10.5\%) and Colorectal Cancer (9.5\%).

Each fatality lost an average of 12.4 years (PYLL) or 7.1 (discounted) years of HALE, with an average associated disability weight (DW) of 0.43 , which reflects the high percentage of deaths in the 75-84 (25\%) and 85+ age groups (41\%) when functional deterioration has set in even amongst healthy persons.

Around 268,206 (95\% CI: 135,362-354,252) hospital days were attributable to Overweight $(98,545)$ and Obesity $(169,464)$, accounting for $16.1 \%$ (95\% CI: $4.5-23.7 \%)$ and $27.6 \%$ (95\% CI: $17.5-34.0 \%$ ) respectively of the 612,844 hospital days associated with related diagnoses (Appendix 2).

Coronary Artery Disease (21.5\%) Type II diabetes (21.1\%), and Hypertension (20.4\%) account for over three-fifths of the 2185 (95\% CI: 878-2667) million NIS direct costs (Table 4) related to overweight (802 million NIS : 95\% CI 51-1122 million NIS) and obesity (1383 million NIS : 95\% CI 827-1545 million NIS).

The ratio of indirect to health service costs from the literature had a median value of $72.2 \%$ (semiinterquartile range 44.7-130.0\%), giving an estimate of 1578 (95\% CI: 977-2841) million NIS for the indirect costs. Therefore, the total costs to society attributable to overweight (1381: 95\% CI 74-2581 million

Table 3 Deaths attributable to overweight or obesity in adults over 20 years old by diagnosis (2016)

\begin{tabular}{|c|c|c|c|c|c|}
\hline & Deaths & Attributable to obesity or overweight & (\%) & Attributable to overweight & Attributable to obesity \\
\hline Coronary artery disease & 4949 & 2207 & $34.5 \%$ & 796 & 1410 \\
\hline Diabetes type II & 941 & 847 & $13.2 \%$ & 315 & 532 \\
\hline Congestive heart failure & 2279 & 822 & $12.8 \%$ & 276 & 546 \\
\hline Stroke & 2742 & 671 & $10.5 \%$ & 224 & 446 \\
\hline Colorectal cancer & 1456 & 609 & $9.5 \%$ & 262 & 347 \\
\hline Hypertension & 846 & 399 & $6.2 \%$ & 142 & 257 \\
\hline Pancreatic cancer & 938 & 344 & $5.4 \%$ & 99 & 245 \\
\hline Pulmonary embolism & 144 & 111 & $1.7 \%$ & 41 & 70 \\
\hline Kidney cancer & 232 & 110 & $1.7 \%$ & 44 & 66 \\
\hline Breast cancer & 1111 & 78 & $1.2 \%$ & 31 & 48 \\
\hline Endometrial cancer & 92 & 55 & $0.9 \%$ & 15 & 40 \\
\hline Ovarian cancer & 292 & 43 & $0.7 \%$ & 18 & 26 \\
\hline Prostate cancer & 394 & 35 & $0.5 \%$ & 27 & 8 \\
\hline Asthma & 116 & 32 & $0.5 \%$ & 10 & 22 \\
\hline Esophageal cancer & 143 & 18 & $0.3 \%$ & 8 & 10 \\
\hline Gallbladder disease & 30 & 10 & $0.2 \%$ & 3 & 7 \\
\hline Non-alcoholic fatty liver & 16 & 6 & $0.1 \%$ & 2 & 4 \\
\hline Gout & 4 & 2 & $0.03 \%$ & 1 & 1 \\
\hline Osteoarthritis & 3 & 2 & $0.03 \%$ & 1 & 1 \\
\hline Total & 16,729 & 6402 & $100 \%$ & 2315 & 4086 \\
\hline
\end{tabular}


Table 4 PAF and direct costs (NIS) attributable to overweight and obesity by diagnoses - Israeli adults (2016)

\begin{tabular}{|c|c|c|c|c|c|}
\hline & PAF overweight & PAF obesity & Total cost & $\begin{array}{l}\text { Attributable to overweight } \\
\text { \& obesity }\end{array}$ & \\
\hline Coronary artery disease & $16.1 \%$ & $28.5 \%$ & $1,055,915,767$ & $470,784,150$ & $21.5 \%$ \\
\hline Diabetes type ॥ & $33.5 \%$ & $56.5 \%$ & $511,313,763$ & $460,182,387$ & $21.1 \%$ \\
\hline Hypertension & $16.8 \%$ & $30.4 \%$ & $943,186,656$ & $445,157,136$ & $20.4 \%$ \\
\hline Congestive heart failure & $12.1 \%$ & $24.0 \%$ & $462,954,791$ & $166,984,682$ & $7.6 \%$ \\
\hline Osteoarthritis & $31.1 \%$ & $35.8 \%$ & $247,895,278$ & $165,852,084$ & $7.6 \%$ \\
\hline Stroke & $8.2 \%$ & $16.3 \%$ & $490,337,015$ & $119,962,933$ & $5.5 \%$ \\
\hline Colorectal cancer & $18.0 \%$ & $23.8 \%$ & $220,788,825$ & $92,322,002$ & $4.2 \%$ \\
\hline Pulmonary embolism & $28.2 \%$ & $48.6 \%$ & $93,633,779$ & $71,915,718$ & $3.3 \%$ \\
\hline Asthma & $8.4 \%$ & $19.1 \%$ & $260,546,602$ & $71,698,574$ & $3.3 \%$ \\
\hline Gallbladder disease & $9.4 \%$ & $23.7 \%$ & $115,622,301$ & $38,181,949$ & $1.7 \%$ \\
\hline Kidney cancer & $19.1 \%$ & $28.5 \%$ & $46,068,752$ & $21,944,698$ & $1.0 \%$ \\
\hline Pancreatic cancer & $10.6 \%$ & $26.1 \%$ & $52,536,885$ & $19,257,766$ & $0.9 \%$ \\
\hline Endometrial cancer & $16.3 \%$ & $44.2 \%$ & $28,576,252$ & $17,298,101$ & $0.8 \%$ \\
\hline Breast cancer & $2.8 \%$ & $4.3 \%$ & $124,719,472$ & $8,786,692$ & $0.4 \%$ \\
\hline Prostate cancer & $6.9 \%$ & $2.0 \%$ & $49,259,925$ & $4,358,259$ & $0.2 \%$ \\
\hline Ovarian cancer & $6.0 \%$ & $8.8 \%$ & $28,750,951$ & $4,263,974$ & $0.2 \%$ \\
\hline Esophageal cancer & $5.7 \%$ & $7.0 \%$ & $23,724,293$ & $3,015,682$ & $0.1 \%$ \\
\hline Non-alcoholic fatty liver & $14.6 \%$ & $22.4 \%$ & $4,413,971$ & $1,633,711$ & $0.1 \%$ \\
\hline Gout & $31.4 \%$ & $16.1 \%$ & $3,409,277$ & $1,618,618$ & $0.1 \%$ \\
\hline Total & & & $6,512,219,714$ & $2,185,219,115$ & $100.0 \%$ \\
\hline
\end{tabular}

NIS) and obesity (2382: 95\% CI 1197-3554 million NIS), amount to around 3763 (95\% CI: 3163-5027) million NIS annually.

The estimate of caries prevalence per person attributable to sugar consumption was 1.25 (in children aged 6.5 years) and 2.51 (in children aged 12.5 years). This translates into an annual per capita caries incidence attributable to sugar of 0.21 for milk teeth and 0.39 for adult teeth respectively (Appendix 3). There is an estimated need for 1.67 million fillings annually in persons under 18 years old, costing around 374 million NIS (at an average cost of 224 NIS per filling). Sugar consumption was estimated to account for around $70.6 \%$ of all caries (and hence potential fillings) in this age group, at a cost of around 264 million NIS annually in Israel.

Hence, the direct and societal costs attributable to obesity, overweight and sugar consumption are 2449 million and 4027 million NIS respectively (both costs including 264 million caries costs attributable to sugar consumption), representing 0.21 and $0.35 \%$ of GDP respectively.

\section{Discussion}

In contrast to deaths which are clearly attributable to a given causality (such as motor vehicle collisions, suicides, falls, fires, drowning etc..), deaths due to pollution and to personal behaviours, such as smoking, sedentariness and nutritional habits are harder to identify. Despite this difficulty, obesity and overweight have been implicated as risk factors for many causes of death [17, 49, 50].

The estimate of 6402 deaths annually attributable to overweight and obesity (around 15\% of all deaths) is over 17 times the magnitude of suicides, 18 times that of road accident fatalities and around 50 times that of homicides in Israel [23]. The direct cost of treating morbidity from overweight and obesity, is around 2.18 billion NIS, equivalent to $0.19 \%$ (95\% CI: $0.08-0.23 \%)$ of Israel's GDP $[23,24]$ or $2.5 \%$ (95\% CI: $1.0-3.9 \%)$ of all health expenditures. This represents an average annual cost of 391 NIS and 802 NIS respectively, for each obese or overweight Israeli aged 20 and over.

The total costs to society of treating morbidity from obesity and overweight, is around 3.8 billion NIS, equivalent to $0.32 \%$ (95\% CI: $0.27-0.43 \%)$ of GDP. $[17,18]$, an average annual expenditure of 674 NIS and 1381 NIS respectively for each obese or overweight Israeli aged 20 and over. Due to the high burden of disease, introduction of programs to reduce sugar consumption are desirable. 


\section{Impact of reducing sugar consumption}

An as yet undefined, national program of reducing energy from sugar consumption from its current level of 12.45 to $10 \%$ will reduce damage from sugar related obesity (and overweight) by $3.7 \%$ over a five year time horizon [7] and reduce caries by $16.1 \%$. This will annually, on average, prevent 237 (95\% CI: 112-325) deaths, 9917 days hospitalization and around 180,000 fillings (Table 5). This will result in annual savings of direct treatment costs of around 121 million NIS (including 40 million NIS from caries reduction) and total societal costs of 180 million (95\% CI: $118-294$ million) NIS or 0.02\% (95\% CI: $0.01-0.03 \%$ ) of GDP (Table 5).

If a more ambitious target of reducing consumption to $5 \%$ is achieved over a 15 year period, sugar related obesity (and overweight) will decrease by $7.7 \%$ [7] and caries by $49.1 \%$. This means that annually an average of 494 (95\% CI: 254-677) deaths, 20,699 days hospitalization and 336,000 fillings will be prevented, resulting in savings of around 244 million NIS in direct costs (including 75 million NIS in caries reduction) and societal costs of 366 million (95\% CI: $239-605$ million) or $0.03 \%$ (95\% CI: $0.02-0.05 \%)$ of GDP.

\section{Cost utility analysis of reducing sugar consumption}

Assuming the imposition of an intervention program will succeed in reducing energy consumption from sugar to $10 \%$ over 5 years, there will be a saving of 1184 lives and 14,703 PYLL, giving a total of 8425 averted discounted DALYS. Since $99.7 \%$ of these DALYS are due to mortality gains, varying the disability weight of hospitalization between 0.2 and 0.4 will have an insignificant effect on the results.

Imposing a tax on sugar products could be part of the multifaceted approach to reducing sugar consumption. Taxing soft drinks could annually generate around 280 million NIS of income (based on adjusted UK estimates). In the UK such revenues are earmarked to improve primary school sports facilities. In Israel, around 24 million NIS of the revenues annually could be earmarked to add 100 full time equivalent dietician posts (including office facilities) to help implement other parts of the multifaceted program to reduce sugar consumption. Over 5 years this hypothetical intervention will for an intervention cost of around 120 million NIS, generate 1400 million in tax revenues, save 606 million NIS in direct treatment

Table 5 Average annual mortality, morbidity decreases and cost savings (NIS) by sugar consumption goals

\begin{tabular}{|c|c|c|c|}
\hline & & Lower 95\% limit & Upper $95 \%$ limit \\
\hline \multicolumn{4}{|l|}{$10 \%$ of energy from sugar in 5 years } \\
\hline \multicolumn{4}{|l|}{ Averted:- } \\
\hline Deaths & 237 & 122 & 325 \\
\hline General hospital days & 9917 & 4993 & 13,068 \\
\hline Caries & 179,625 & 153,843 & 205,050 \\
\hline \multicolumn{4}{|l|}{ Savings (NIS):- } \\
\hline Fewer fillings & $40,276,302$ & $34,495,259$ & $45,977,166$ \\
\hline Overweight \& obesity treatment & $80,854,527$ & $47,172,679$ & $143,248,124$ \\
\hline Total direct costs (NIS): & $121,130,829$ & $81,667,937$ & $189,225,290$ \\
\hline Indirect costs & $58,375,715$ & $36,166,004$ & $105,129,999$ \\
\hline Total societal costs (NIS) & $179,506,544$ & $117,833,941$ & $294,355,290$ \\
\hline$\%$ of per capita GDP & $0.02 \%$ & $0.01 \%$ & $0.03 \%$ \\
\hline \multicolumn{4}{|l|}{$5 \%$ of energy from sugar in 15 years } \\
\hline \multicolumn{4}{|l|}{ Averted:- } \\
\hline Deaths & 494 & 254 & 677 \\
\hline General hospital days & 20,699 & 10,423 & 27,277 \\
\hline Caries & 336,484 & 288,187 & 384,111 \\
\hline \multicolumn{4}{|l|}{ Savings (NIS):- } \\
\hline Fewer fillings & $75,447,779$ & $64,618,411$ & $86,126,949$ \\
\hline Overweight \& obesity treatment & $168,767,366$ & $98,463,364$ & $299,001,300$ \\
\hline Total direct costs (NIS): & $244,215,145$ & $163,081,775$ & $385,128,250$ \\
\hline Indirect costs & $121,847,423$ & $75,489,171$ & $219,437,473$ \\
\hline Total Societal Costs (NIS) & $366,062,568$ & $238,570,946$ & $604,565,723$ \\
\hline$\%$ of per capita GDP & $0.03 \%$ & $0.02 \%$ & $0.05 \%$ \\
\hline
\end{tabular}


costs and a further 292 million in indirect costs, resulting in a net (cost-) saving of 2178 million NIS.

However, the Health Minister is reluctant to impose a sugar tax, on the grounds that such a tax will raise consumer prices in a regressive fashion [11]. In this scenario, the intervention will still be cost saving to the tune of 778 million NIS. While any future imposition of a sugar tax will impose only a small legislative cost, lessons should be learned from the recent experience in New York of the practical problems of imposing such a tax, especially in that it should be based on a per calorie as opposed to per volume formula [50].

These estimates, of damage from sugar consumption, should be regarded as preliminary as they can be improved upon if the following data ever becomes available:

i) Israeli-based cause and age-specific relative risks, thus allowing calculation of PAF due to obesity and overweight in Israel.

ii) Israeli based disease specific costs and utilization rates of geriatric hospitals, out of hospital pharmaceutical and other care costs (home helps, physiotherapy, ambulatory doctor visits etc.).

iii) Israeli-based cause specific estimates of work productivity losses and other indirect costs.

iv) Estimates of disability weights relating to morbidity in an out-of hospital setting. This would correct for the underestimation of DALYS averted (and subsequent overestimation of Costs per DALY averted) since only estimates for morbidity losses during the period of hospitalisation were included in the model.

Gains from reduced caries might also be overestimated to the extent that some people in Israel are already exposed to fluoride via toothpaste and their natural water supplies. On the other hand, estimates of the costs of treating caries and hence potential savings attributable to reductions in sugar consumption can be considered as being very conservative as they do not include any costs incurred by persons aged 18 years and over, who will almost certainly benefit from a reduction in sugar consumption [51].

Further underestimations of averted DALYS and averted treatment costs arose because the model was based solely on the relative risks of overweight and obese persons and was unable (because of lack of data) to take into account the impact of reductions in sugar consumption in persons of normal weight. For example, many new onset cases of type II diabetes occur in persons of normal anthropometric proportions who would also benefit from reduction in sugar consumption [52].

All the estimates are subject to the important caveat that any achieved calorific reduction due to decreased sugar consumption is not compensated for by increased calorific intake of other (non-sugar) foods. But even in the event that a compensating rise in calorific consumption occurs (resulting possibly in an isocaloric situation), some health benefits are likely to still be generated as "not all calories are equal" since there is evidence that the quality of fat and carbohydrate can play a more important role than the quantity [53]. The resultant diet that is lower in sugar (carbohydrates) is likely be healthier than the initial high in sugar diet, especially with respect to type II diabetes risk factors in young people [54]. If full calorific compensation occurs, then the mortality and morbidity gains estimated in this paper will be around $74 \%$ lower [55], resulting in there being a gain of 2190 DALYs and a net saving of only 113 million NIS in the scenario where no tax is imposed on sugar.

Reducing energy from sugar consumption from its current level of 12.45 to $10 \%$, over a five year time horizon is considered to be a very reasonable and attainable short-term goal. Over these 5 years, this would save 2178 million NIS in costs (778 million NIS if no taxes are imposed) as well as 1184 lives. Achieving a reduction to $5 \%$ over a 15 year period would be a far harder goal to achieve, but the rewards in terms of decreased mortality, morbidity and expenditures would be greater.

It is highly likely that any package of interventions, with or without the imposition of taxes on sugar, will be cost-saving (i.e. supplying quality adjusted life years at no additional net cost), since costs savings from morbidity reductions (and possible tax revenues) will exceed the costs of the intervention. This will still be true if we view the results just from just the direct costs of health services perspective. Finally, it should be noted that other many other interventions available to reduce overweight and obesity are available, that have also been shown to be cost-saving or very cost effective [21, 56].

\section{Conclusions}

Sugar consumption causes a huge monetary and mortality burden. Estimates of potential decreases in this burden justify the current prioritisation given by the health minister of creating and implementing a national program to reduce sugar consumption, which is likely to be cost-saving (ie: averted treatment costs will exceed intervention costs). 


\section{Appendix 1}

Table 6 Direct costs (NIS by type) of comorbidities related to overweight and obesity in Israeli adults (2016)

\begin{tabular}{|c|c|c|c|c|c|}
\hline & Hospital care & Other care & Drugs excl hosp & Total cost & \\
\hline Coronary artery disease & $591,658,411$ & $242,594,993$ & $221,662,363$ & $1,055,915,767$ & $22.2 \%$ \\
\hline Hypertension & $61,099,650$ & $395,143,788$ & $486,943,218$ & $943,186,656$ & $19.8 \%$ \\
\hline Diabetes type II & $206,869,057$ & $181,625,245$ & $122,819,461$ & $511,313,763$ & $10.7 \%$ \\
\hline Stroke & $370,683,266$ & $112,966,069$ & $6,687,680$ & $490,337,015$ & $10.3 \%$ \\
\hline Congestive heart failure & $296,083,592$ & $105,115,078$ & $61,756,121$ & $462,954,791$ & $9.7 \%$ \\
\hline Asthma & $41,796,206$ & $109,329,885$ & $109,420,510$ & $260,546,602$ & $5.5 \%$ \\
\hline Osteoarthritis & $108,937,052$ & $75,063,697$ & $63,894,529$ & $247,895,278$ & $5.2 \%$ \\
\hline Colorectal cancer & $144,207,495$ & $64,220,043$ & $12,361,287$ & $220,788,825$ & $4.6 \%$ \\
\hline Breast cancer & $47,387,005$ & $56,090,016$ & $21,242,451$ & $124,719,472$ & $2.6 \%$ \\
\hline Gallbladder disease & $77,257,439$ & $30,853,722$ & $7,511,140$ & $115,622,301$ & $2.4 \%$ \\
\hline Pulmonary embolism & $52,141,557$ & $23,642,864$ & $17,849,358$ & $93,633,779$ & $2.0 \%$ \\
\hline Pancreatic cancer & $35,098,638$ & $14,772,528$ & $2,665,719$ & $52,536,885$ & $1.1 \%$ \\
\hline Prostate cancer & $22,111,658$ & $21,229,074$ & $5,919,193$ & $49,259,925$ & $1.0 \%$ \\
\hline Kidney cancer & $26,858,616$ & $15,474,832$ & $3,735,304$ & $46,068,752$ & $1.0 \%$ \\
\hline Ovarian cancer & $19,039,091$ & $8,197,386$ & $1,514,473$ & $28,750,951$ & $0.6 \%$ \\
\hline Endometrial cancer & $14,533,230$ & $10,957,594$ & $3,085,428$ & $28,576,252$ & $0.6 \%$ \\
\hline Oesophageal cancer & $16,018,731$ & $6,573,203$ & $1,132,359$ & $23,724,293$ & $0.5 \%$ \\
\hline Non-alcoholic fatty liver & $2,054,218$ & $1,341,950$ & $1,017,803$ & $4,413,971$ & $0.1 \%$ \\
\hline Gout & $1,586,644$ & $1,036,499$ & 786,134 & $3,409,277$ & $0.1 \%$ \\
\hline Total & $2,135,421,555$ & $1,476,228,468$ & $1,152,004,532$ & $4,763,654,555$ & $100.0 \%$ \\
\hline
\end{tabular}

\section{Appendix 2}

Table 7 Hospital days attributable to overweight and obesity in Israeli adults (2016)

\begin{tabular}{|c|c|c|c|c|}
\hline & Days & Overweight & Obesity & Normal or underweight \\
\hline Coronary artery disease & 169,800 & 27,316 & 48,390 & 94,094 \\
\hline Diabetes type ॥ & 59,369 & 19,962 & 33,470 & 5937 \\
\hline Congestive heart failure & 84,973 & 10,285 & 20,364 & 54,324 \\
\hline Stroke & 106,382 & 8707 & 17,320 & 80,355 \\
\hline Osteoarthritis & 31,264 & 9733 & 11,183 & 10,347 \\
\hline Colorectal cancer & 41,386 & 7451 & 9855 & 24,081 \\
\hline Pulmonary embolism & 14,964 & 4215 & 7278 & 3471 \\
\hline Hypertension & 17,535 & 2942 & 5334 & 9259 \\
\hline Gallbladder disease & 22,172 & 2075 & 5247 & 14,850 \\
\hline Pancreatic cancer & 10,073 & 1063 & 2629 & 6381 \\
\hline Kidney cancer & 7708 & 1474 & 2198 & 4036 \\
\hline Asthma & 11,995 & 1008 & 2293 & 8694 \\
\hline Endometrial cancer & 4171 & 680 & 1844 & 1646 \\
\hline Breast cancer & 13,600 & 375 & 583 & 12,641 \\
\hline Ovarian cancer & 5464 & 329 & 482 & 4654 \\
\hline Esophogal cancer & 4597 & 263 & 321 & 4013 \\
\hline Prostate cancer & 6346 & 436 & 125 & 5784 \\
\hline Non-alcoholic fatty liver & 590 & 86 & 327 & 177 \\
\hline Gout & 455 & 143 & 221 & 91 \\
\hline Total & 612,844 & 98,545 & 169,464 & 344,835 \\
\hline
\end{tabular}




\section{Appendix 3}

Table 8 Relationship between caries incidence attributable to sugar consumption in Israel

\begin{tabular}{lll}
\hline & Milk teeth & Adult teeth \\
\hline Age of child (years) $^{\mathrm{a}}$ & 6.5 & 12.5 \\
Caries with zero sugar (intercept) $^{\mathrm{a}}$ & 2.13 & 0.06 \\
Caries per gm per person day $^{\mathrm{a}}$ & 0.02 & 0.04 \\
Caries prevalence from sugar $^{\mathrm{b}}$ & 1.25 & 2.51 \\
\% of caries from sugar $^{\text {Tooth years of exposure }}$ & $37 \%$ & $98 \%$ \\
Sugar consumption (Kgm) $^{\mathrm{c}}$ & 94 & 72 \\
Caries per Kgm sugar consumption $^{\text {A }}$ & 137 & 149 \\
Annual caries incidence per person $^{\mathrm{d}}$ & 0.009 & 0.017 \\
\hline
\end{tabular}

\section{Notes:-}

abased on regressions from international cross-sectional study [36]

based on Israeli consumption of $62.7 \mathrm{~g} /$ day

cfrom 6 months to 6.5 years for milk teeth and 6.0 years to 12.5 years for adult teeth

dattributable to sugar

\section{Abbreviations}

BMI: Body Mass Index; DALY: Disability adjusted life year; GDP: Gross Domestic Product; HALE: Healthy Adjusted Life Expectancy; NIS: New Israeli shekel; PAF: Population attributable fraction; PYLL: Potential Years of Life Lost; RR: Relative risk; UK: United Kingdom of Great Britain and Northern Ireland; WHO: World Health Organization

\section{Acknowledgements}

Tziona Haklai and Dr. Nehama Goldberger of the Health Ministry's Information Division for supplying the raw mortality and hospitalization data. Dr Tami Shohat of the Israel Center for Disease Control for BMI survey data. Dr. David Yalon and Dr. Ziah Awad of the Dental Division of the Ministry of Health for dental survey and cost data.

\section{Funding}

"Not applicable". The author is a salaried staff member of the Ministry of Health.

\section{Availability of data and materia}

The data from the spreadsheets analyzed during the current study are available from the corresponding author on reasonable request.

\section{Authors' contributions}

Dr Ginsberg designed the study, collected the data, built the mode, carried out the data analysis, wrote the initial and wrote, read and approved the final manuscript.

\section{Competing interests}

The sole author is a salaried staff member of the Ministry of Health and there are no competing interests to declare. All persons who supplied data are also directly or indirectly salaried staff funded by the Ministry of Health.

\section{Consent for publication}

Not Applicable.

\section{Ethics approval and consent to participate}

As the study is based on published literature and a built spreadsheet, no human subjects were involved - hence there is no need to provide ethics approval and consent to participate.
Received: 18 August 2016 Accepted: 19 December 2016

Published online: 10 January 2017

\section{References}

1. Obesity Key facts WHO factsheet. http://www.who.int/mediacentre/ factsheets/fs311/en/. Accessed 29 Dec 2016.

2. World Health Organization. Obesity: preventing and managing the global epidemic, Technical Report Series No. 894. Geneva: WHO; 2000.

3. Ginsberg G, Rosen B, Rosenberg E. Cost-utility analysis cost-utility analyses of interventions to increase exercise in Israeli adults. RR-565-11, BrookdaleSmokler Center for Health Policy Research. http://brookdale.jdc.org.il/ Uploads/PublicationsFiles/RR-565-11-Physical-Exercise-English-report.pdf. Accessed 29 Dec 2016.

4. Traversey G, Chaput J-P. Alcohol consumption and obesity: an update. Curr Obes Rep. 2015:4(1):122-30. doi:10.1007/s13679-014-0129-4. Published online 2015 Jan 8

5. Patel SR, Hayes AL, Blackwell T, the Osteoporotic Fractures in Men (MrOS) and the Study of Osteoporotic Fractures (SOF) Research Groups, et al. The association between sleep patterns and obesity in older adults. Int J Obes (Lond). 2014;38:1159-64. doi:10.1038/ijo.2014.13. Published online 2014 Jan 24

6. The Scientific Advisory Committee on Nutrition. Carbohydrates and health. 2015. Online. Available from: https://www.gov.uk/government/groups/ scientific-advisory-committee-on-nutrition. Accessed 29 Dec 2016.

7. Tedstone A, Targett V, Allen R, staff at PHE. Public Health England, London. Sugar reduction: the evidence for action. 2015.

8. Department of Health. Dietary sugars and human disease. Report on the panel on dietary sugars. London: HMSO; 1989. p. 37.

9. Escobar MAC, Veerman JL, Tollman SM, Bertram MY, Hofman KJ. Evidence that a tax on sugar sweetened beverages reduces the obesity rate: a metaanalysis. BMC Public Health. 2013;13:1072. http://www.biomedcentral.com/ 1471-2458/13/1072. Accessed 29 Dec 2016.

10. Nitzan-Kaluski D, Berry EM. Prevalence of obesity in Israel. Obes Rev. 2005;6:115-6.

11. Dovrat-Meseritz A. New Israeli health-labeling rules less strict than food makers feared. Haaretz (Newspaper). 2016. http://www.haaretz.com/israelnews/business/1.754454. Accessed 29 Dec 2016.

12. Israel National Health Interview Survey INHIS-1, 2003-2004. Selected findings. Israel: Center for Disease Control, Ministry of Health; 2006. http:// www.health.gov.il/publicationsfiles/inhis 1.pdf. Accessed 29 Dec 2016.

13. Israel National Health Interview Survey INHIS-2, 2007-2010. Selected findings. Israel: Center for Disease Control, Ministry of Health; 2012. http:// www.health.gov.il/publicationsfiles/inhis_2.pdf. Accessed Dec 292016.

14. Israel National Health Interview Survey INHIS-3, 2013-2015. Selected findings. Israel: Center for Disease Control, Ministry of Health; 2016. http://www.health. gov.il/publicationsfiles/inhis_3main_findings.pdf. Accessed 29 Dec 2016

15. First National Health and Nutrition Survey, 1999-2001. Section A, General findings. Israel: Center for Disease Control, Ministry of Health; 2003. p. 225. Publication.

16. National Health and Nutrition Survey of the over 65s, 2005-2006. Section A, General findings. Israel: Center for Disease Control, Ministry of Health; 2010. p. 327. Publication

17. Anis AH, Zhang W, Bansback N, Guh DP, Amarsi Z, Birmingham CL. Obesity and overweight in Canada: an updated cost-of-illness study. Obes Rev. 2010;11:31-40. Epub 2009 Apr 21.

18. Bell JA, Kivimaki M, Hamer M. Metabolically healthy obesity and risk of incident type 2 diabetes: a meta-analysis of prospective cohort studies. Obes Rev. 2014;15:504-15. doi:10.1111/obr.12157.

19. Li L, Liu DW, Yan HY, Wang ZY, Zhao SH, Wang B. Obesity is an independent risk factor for non-alcoholic fatty liver disease: evidence from a meta-analysis of 21 cohort studies. Obes Rev. 2016;17l:510-9. doi:10.1111/ obr.12407. Epub 2016 Mar 28.

20. Aune D, Norat T, Vatten LJ. Body Mass Index and the Risk of Gout: a systematic review and dose-response meta-analysis of prospective studies. Eur J Nutr. 2014;53:1591-601. doi:10.1007/s00394-014-0766-0. Epub 2014 Sep 11

21. Ginsberg G, Rosenberg E. Economic effects of interventions to reduce obesity in Israel. Israel J Health Policy Res. 2012;1:17. doi:10.1186/2045 4015-1-17.

22. Central Bureau of Statistics. Statistical Abstract of Israel 2014 No 65. Jerusalem. 2014. http://www.cbs.gov.il/reader/shnaton/shnatone new. htm?CYear=2014\&Vol=65\&CSubject=30. Accessed 29 Dec 2016. 
23. Central Bureau of Statistics. Statistical Abstract of Israel 2015 no 66. Jerusalem. 2015. http://www.cbs.gov.il/reader/shnaton/shnatone_new. htm?CYear=2015\&Vol=66\&CSubject=30. Accessed 29 Dec 2016.

24. Central Bureau of Statistics. Monthly bulletin of statistics - June 2016. Jerusalem. 2016. http://www.cbs.gov.il/webpub/pub/text_page_eng. html?publ=93. Accessed 29 Dec 2016.

25. Ministry of Health. Price list for ambulatory and hospitalization services onset date: 01/06/16. http://www.health.gov.il/subjects/finance/taarifon/ pages/pricelist.aspx. Accessed 29 Dec 2016.

26. Ginsberg G, Kark J, Einav S. Is out-of-hospital resuscitation worthwhile? CostUtility Analysis of Cardiac Resuscitation Services in Jerusalem. Resuscitation. 2015;86:54-61.

27. Colditz GA. Economic costs of obesity and inactivity. Med Sci Sports Exerc. 1999;31:S663-7.

28. Colagiuri S, Lee CMY, Colagiuri R, et al. The cost of overweight and obesity in Australia. Med J Aust. 2010;192:260-4

29. National Audit Office. Tackling obesity in England. Report by the Comptroller and Auditor General. HC220 Session 2000-2001, 15th February; 2001. https://www.nao.org.uk/wp-content/uploads/2001/02/0001220.pdf Accessed 29 Dec 2016.

30. Finklestein EA, DiBonaventura MC, Burgess SM, Hale BC. J Occup Environ Med. 2010;52:971-6.

31. Goetzl RZ, Gibson TB, Short ME, Chu B-C, Wadell J, Bowen J, Lemon SC, Fernandez ID, Ozminkowski RJ, Wilson MG, DeJoy DM. A multi-worksite analysis of the relationships among body mass index, medical utilization, and worker productivity. J Occup Environ Med. 2010;1:S52-8.

32. Kang JH, Jeong BG, Cho YG, Song HR, Kim KA. Socioeconomic costs of overweight and obesity in Korean adults. J Korean Med Sci. 2011;26:153340. http://dx.doi.org/10.3346/jkms.2011.26.12.1533. Accessed 29 Dec 2016.

33. Konnopka A, Bodemann N, Konig H-H. Health burden and costs of obesity and overweight in Germany. Eur J Health Econ. 2011;12:345-52. doi:10.1007/ s10198-010-0242-6.

34. Kreuger H, Williams D, Ready AE, Trenaman L, Turner D. Improved estimation of the health and economic burden of chronic disease risk factors in Manitoba. Chron Dis Inj Can. 2013;33:236-46.

35. Lal A, Moodie M, Ashton T, Siahpush M, Swinburn B. Health care and lost productivity costs of overweight and obesity in New Zealand. Aust N Z J Public Health. 2012;36:550-6.

36. Levy E, Levy P, LePen C, Basdevant A. The economic cost of obesity: the French situation. Int J Obes (Lond). 1995:19:788-92.

37. Lehert T, Streltchenia P, Konnopka A, Riedel-Heller SG, Konig H-H. Health burden and costs of obesity and overweight in Germany: an update. Eur J Health Econ. 2015;16:957-67.

38. Moffat E, Shack LG, Petz GJ, Sauve JK, Hayward K, Colman R. The cost of obesity and overweight in 2005: A case study of Alberta, Canada. Can J Public Health. 2011;102:144-8.

39. Sander B, Beregemann R. Economic burden of obesity and its complications in Germany. Eur J Health Econ. 2003;4:248-52.

40. House of Commons Health Select Committee. Obesity: third report of session 2003/2004. London: The Stationery Office; 2004. https://www. publications.parliament.uk/pa/cm200304/cmselect/cmhealth/23/23.pdf. Accessed 29 Dec 2016

41. Wolf AM, Colditz GA. Current estimates of the economic cost of obesity in the United States. Obes Res. 1998;6:97-106.

42. Sreebny LM. Sugar availability, sugar consumption and dental caries. Community Dent Oral Epidemiol. 1982;10:1-7.

43. Tedstone A, Targett $\mathrm{V}$, Allen $\mathrm{R}$, staff at PHE. Sugar reduction: the evidence for action. Annexe 1b. Impact assessment - modelling potential health and other benefits of achieving SACN recommendations for sugar. London: Public Health England; 2015.

44. Iheozor-Ejiofor Z, Worthington HV, Walsh T, et al. Water fluoridation for the prevention of dental caries. Cochrane Database Syst Rev. 2015;6:CD010856. doi:10.1002/14651858.CD010856.pub2.

45. Cohen R, Rabin H. National Insurance Institute: Kupat Holim Membership 2014 Periodic survey number 271, Jerusalem September; 2015. https:// www.btl.gov.il/Publications/survey/Documents/seker_271.pdf Accessed 29 Dec 2016

46. WHO Commission on MacroEconomics and Health. Macroeconomics and Health: investing in health for economic development. Report of the Commission on Macroeconomics and Health. Geneva: World Health Organization; 2001
47. Central Bureau of Statistics. Macro-Economics Statistics Quarterly No 2016/1. Jerusalem, January-March; 2016. http://www.cbs.gov.il/webpub/pub/text_ page_eng.html?publ=41. Accessed 29 Dec 2016.

48. Gander K. "Budget 2016: George Osborne announces sugar tax on soft drinks industry". The Independent. 2016. https://en.wikipedia.org/wiki/ Sugary_drinks_tax\#cite_ref-35. Accessed 29 Dec 2016.

49. Guh DP, Zhang W, Bansback N, Amarsi Z, Birmingham CL, Anis AH. The incidence of co-morbidities related to obesity and overweight: a systematic review and meta-analysis. BMC Public Health. 2009;9:88. doi:10.1186/14712458-9-88.

50. Isett KR, Laugesen MJ, Cloud DH. Learning from New York City: a case study of public health policy practice in the Bloomberg administration. J Public Health Manag Pract. 2015;21(4):313-22. doi:10.1097/PHH.0000000000000225.

51. Birmingham CL, Muller JL, Palepu A, Spinelli JJ, Anis AH. The cost of obesity in Canada. CMAJ. 1999;160:483-8.

52. Hu FB, Manson JE, Stampfer MJ, et al. N Engl J Med. 2001;345:790-7.

53. Schulze MB, Hu FB. Primary prevention of diabetes: What can be done and how much can be prevented? Annu Rev Public Health. 2005;26:445-67.

54. Gow ML, Garnett SP, Baur LA, Lister NB. The effectiveness of different diet strategies to reduce type 2 diabetes risk in youth. Nutrients. 2016;8:8. doi:10. 3390/nu8080486.

55. Sanchez-Romero LM, Penko J, Coxson PG, et al. Projected impact of Mexico's sugar sweetened beverage tax policy on diabetes and cardiovascular disease: a modeling study. PLoS Med. doi:10.1371/journal. pmed.1002158. Nov 1, 2016.

56. Cost-Utility Analyses of Interventions to Prevent and Treat Obesity in Israel. The Smokler Center for Health Policy Research, RR-550-09 Jerusalem January; 2010. http://brookdale.jdc.org.il/_Uploads/PublicationsFiles/550-10Obesity-REP-ENG.pdf. Accessed 29 Dec 2016.

\section{Submit your next manuscript to BioMed Central and we will help you at every step:}

- We accept pre-submission inquiries

- Our selector tool helps you to find the most relevant journal

- We provide round the clock customer support

- Convenient online submission

- Thorough peer review

- Inclusion in PubMed and all major indexing services

- Maximum visibility for your research

Submit your manuscript at www.biomedcentral.com/submit
C) Biomed Central 